\title{
Estimation of sugars and volatiles in the Honeydew of Bemisia tabaci genetic groups Meam-I and Asia-I
}

\author{
H. K. Roopa ${ }^{1 \star}$, R. Asokan ${ }^{1, N}$ N. K. Krishna Kumar², Riaz Mahmood³, N. Bakthavatsalam, K. \\ Uprithi $^{5}$ and A. Raghavendra ${ }^{4}$
}

\author{
${ }^{1}$ Division of Biotechnology, Indian Institute of Horticultural Research, Hessaraghatta Lake P.O Karnataka, Bengaluru \\ 560089 , India. \\ ${ }^{2}$ Regional Representative, South and Central Asia, Bioversity International, New Delhi 110 012, India. \\ ${ }^{3}$ Department of Biotechnology and Bioinformatics, Kuvempu University, Jnanasahyadri, Shankaraghatta, Shimoga 577 \\ 451, India. \\ ${ }^{4}$ Division of Insect Ecology, National Bureau of Agricultural Insect Resources, Bengaluru 560024. India. \\ ${ }^{5}$ Division of Biochemistry and physiology, Indian Institute of Horticultural Research, Hessaraghatta Lake P.O Karnataka, \\ Bengaluru 560 089, India. \\ *Corresponding author. Email: roopa21hk@gmail.com
}

Copyright @ 2016 Roopa et al. This article remains permanently open access under the terms of the Creative Commons Attribution License 4.0, which permits unrestricted use, distribution, and reproduction in any medium, provided the original work is properly cited.

Received 8th August, 2016; Accepted 17th September, 2016

\begin{abstract}
Bemisia tabaci (Gennadius) is a species complex, affecting wide varieties of crops globally, mainly a dreaded vector of Gemini viruses. It also causes extensive damage as a pest through direct feeding on the phloem sap and impacting crop yield by excreting copious amounts of honeydew. Sugars of honeydew serve as an excellent source for predators and parasitoids in pursuing their prey. In addition, the volatiles emitted by microbes in the honeydew are reported to attract the natural enemies of sucking pests. In the present study, an attempt was made to estimate sugars and identify volatiles in the honeydew of $B$. tabaci genetic groups viz; MEAM-I and Asia-I. HPLC analysis revealed that ribose sugar was highest in both phloem sap and honeydews followed by glucose, sucrose, and fructose. GC-MS result revealed volatiles, $\mathrm{n}$-nonane, $\mathrm{n}$-decane, 2-methyldecane, o-cymene benzene, $\mathrm{n}$-undecane, propyl disulfide, $\mathrm{n}$-dodecane, disulfide, bis (1-methylpropyl) are common in B. tabaci genetic groups.
\end{abstract}

Key words: Bemisia tabaci, honeydew, carbohydrates, volatiles.

\section{INTRODUCTION}

Hemipterans suck phloem sap and excrete the unassimilated components in the form of honeydew (Golan and Najda, 2011). Major sucking pests whitefly aphids, mealybugs, thrips infest and feed on host plant affecting crop yield. The whitefly Bemisia tabaci (Gennadius) (Hemiptera: Aleyrodidae) is a prominent invasive species notorious for its extensive feeding, ability to spread Geminiviruses as a vector. Improper management measures using insecticides has led to emergence of resistant individuals hindering prevention and eradication measures. B. tabaci is part of a species complex which are morphologically indistinguishable biotypes/cryptic species/genetic groups (Dinsdale et al., 2010; De Barro et al., 2011; Liu et al., 2012). The taxonomic evaluation of the species complex structure can be resolved only through ribosomal internal transcribed spacer 1 (rDNA ITS-1) and mitochondrial cytochrome oxidase-I (mtDNA COI) sequences worldwide (Simon et al., 1994; Hu et al., 2011; Zasada et al., 2014; Dinsdale et al., 2010). Following the direct damage imparted by excessive phloem sap feeding, the honeydew excreted from $B$. tabaci support the growth of sooty mold fungi, e.g. Capnodium spp., which inhibits host photosynthesis (Johnson et al., 1991). The process 
of excretion, its rate and quantity from insect's body varies with different species. In case of whiteflies, honeydew flows through vasiform orifice and is then ejected from the body.

Wool et al, (2006) reported around 20 different sugars in the honeydew of aphids, of which glucose and fructose are basic components of the honeydew of these sap sucking insects (Wilkinson et al., 1997; Fischer et al., 2005; Wool et al., 2006). The proportion of these sugars in honeydew is species-specific and depends on host plan, thereby indicating the diverse metabolic mechanisms in insects (Volkl et al., 1999; Fischer and Shingleton, 2001; Wool et al., 2006). The crucial factor contributing to the aforesaid uncertainty is supposed to be the sugar transformations compounded by bacteria associated with the insects. Nymphs and adults of whitefly, B. tabaci feed on cotton plant phloem sap, which contains predominantly sucrose (Hendrix et al., 1992). The disaccharide, trehalulose is reported as a major component of B. tabaci honeydew (Byrne and Miller, 1990; Tarczynski et al., 1992; Hendrix and Wei, 1994). Honeydew of $B$. tabaci and Trialeurodes vaporariorum (Westwood) as dietary resources reported to be important for egg production and longevity in case of Encarsia formosa Gahan (Burger et al., 2004). Trehalose and trehalulose have already been described as components of Myzus persicae and B. tabaci honeydew (Fisher et al., 1984; Bates et al., 1990). Trehalulose was first identified in B. tabaci (Byrne and Miller, 1990). Later Hendrix and Wei (1994) identified bemisiose as another unusual trisaccharide. Isaacs et al. (1998), studying the composition of cucurbit phloem sap and B. tabaci honeydew, suggested that glucose made up to $60 \%$ of the honeydew sugars. The plant sap contained low levels of sucrose and raffinose. However, no sucrose or melezitose were detected in any honeydew samples. Davidson et al. (1994) suggested that the unusual disaccharide trehalulose, an important constituent in honeydew of $B$. argentifolii, is produced by obligate intracellular microorganisms residing in this insect's mycetomes.

Honeydew plays important role as kairomone in hostsearching of parasitoids leads to important ecological consequences. B. tabaci honeydew not only contains sugars and traces of amino acids, it also emits volatiles acing as kairomones for parasitoids and predators. Liu et al, (2007) reported the presence of volatile Bis (2ethylhexyl) phthalate in honeydew from both $B$. tabaci on cabbage and $T$. vaporariorum on cucumber. However, the identification of the semiochemicals or volatiles released from honeydew of $B$. tabaci genetic groups from cotton has not yet been studied. Hence, it would be of great importance to identify the sugars and volatiles present in honeydew of $B$. tabaci genetic groups in particular (Middle East Asia Minor-I) MEAM-I and native genetic group Asia-I. This can provide basic information in formulating eco-friendly management of many sucking pests and insect vectors including whiteflies.

\section{MATERIAL AND METHODS}

\section{Insect Culture}

B. tabaci genetic groups namely Asia-II-7 and MEAM - I were collected from Bengaluru $12^{\circ} 58^{\prime} \mathrm{N}, 77^{\circ} 38^{\prime} \mathrm{E}$ and Kolar $13^{\circ} 09^{\prime} \mathrm{N}, 78^{\circ} 11^{\prime}$ E Karnataka, India respectively. The culture were maintained on cotton (Gossypium hirsutum) as described by Byrne and Miller, (1990). Morphological identification was carried as per Brown (1997) and Martin (1987). The host plants were cultivated (12h light photoperiod: $65 \pm 5 \%$ relative humidity $[\mathrm{RH}] ; 30$ $\pm 2^{\circ} \mathrm{C}$ temperature) in separate glasshouses at Indian Institute of Horticultural Research.

\section{Honeydew collection for HPLC}

Fresh honeydew drops from nymphs were collected using $2 \mu \mathrm{l}$ pipette and a measured quantity drawn and preserved in $-80^{\circ} \mathrm{C}$ until further use. Phloem sap was collected based on method described using EDTAfacilitated exudation (Tetyuk et al., 2013).

\section{Honeydew collection for Gas Chromatography Mass Spectrum (GC MS) analysis}

Fresh B. tabaci honeydew samples were collected in a Petriplate, soaked overnight in $5 \%$ potassium dichromate and then washed with double distilled water to remove traces of hydrocarbons. The clean plates were dried in a hot air oven and placed below heavily infested leaves. The honeydew volatiles were collected in High Performance Liquid Chromatography (HPLC) graded Hexane (Sigma-Aldrich ${ }^{\circledR}$ ) and stored in glass tubes at $80^{\circ} \mathrm{C}$ till GC-MS analysis. The honeydew excretion through vasiform orifice of the insect and its fungal infection were captured using Olympus SZX7 stereomicroscope with Q-imaging software (Figure 1).

\section{Estimation of sugars by High Performance Liquid Chromatography (HPLC)}

Sugars from honeydew were analyzed by HPLC with slight modifications (Sanchez-Mata et al., 2002). The Shimadzu (kyoto, Japan) Prominence HPLC system equipped with a refractive index detector (RID; Model $10 \mathrm{~A}$, Shimadzu) and $\mathrm{NH}_{2}$ reversed phase column $(25 \mathrm{~cm}$ x $4.6 \mathrm{~mm}, 5 \mu \mathrm{m}$, Supelco, Bellefonte, PA, USA) were used for the purpose. Both RID cell and column temperature were kept at $40^{\circ} \mathrm{C}$ during the analysis. The mobile phase consisted of water: acetonitrile $(50: 50, \mathrm{v} / \mathrm{v})$ at a flow rate 

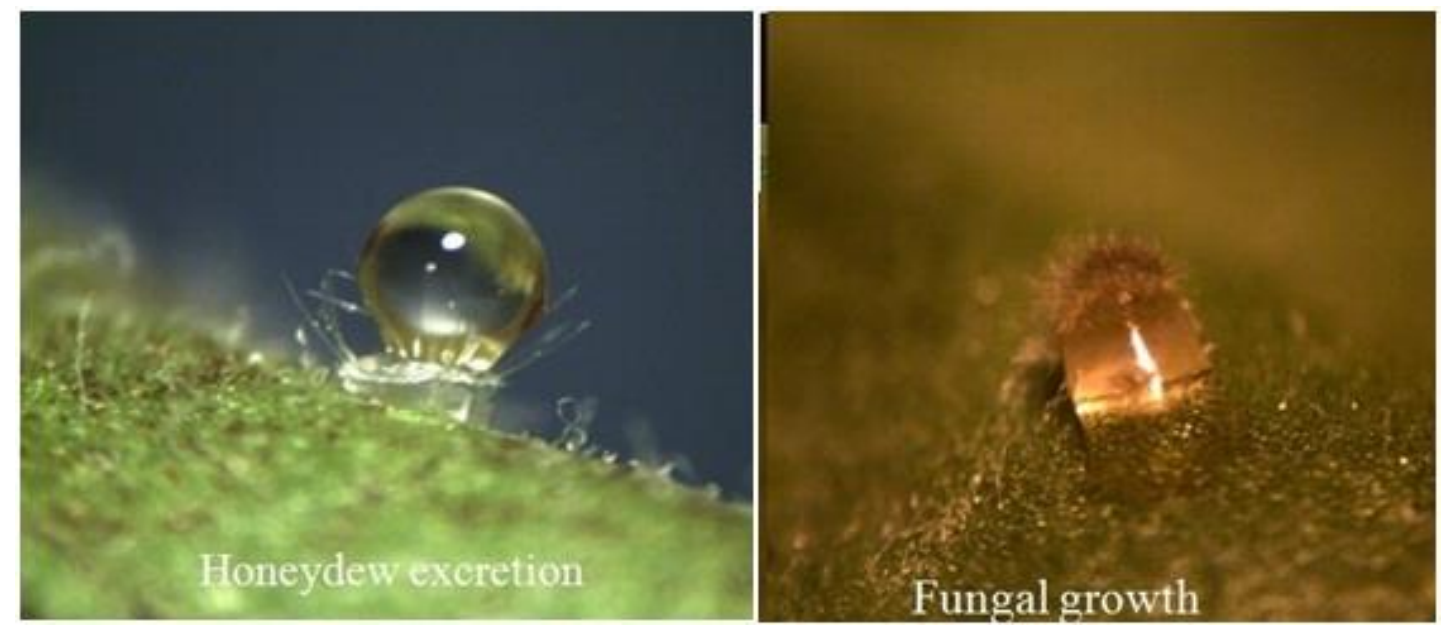

Figure 1. Honeydew excreted from vasiform orifice of $B$. tabaci nymphs and its fungal growth were captured using Olympus SZX7 stereomicroscope with Q-imaging software.

Table 1. Indicates the percentage of various sugars present in honeydew samples and plant sap,

\begin{tabular}{lllllllll}
\hline Sample & Ribose & Glucose & Sucrose & Fructose & Trehalose & Arabinose & Maltose & Melezitose \\
\hline Phloem Sap & $40.54 \pm 0.03$ & $18.03 \pm 0.06$ & $12.39 \pm 0.03$ & $11.76 \pm 0.12$ & $4.23 \pm 0.40$ & $5.57 \pm 0.41$ & $6.08 \pm 0.39$ & $1.41 \pm 0.18$ \\
MEAM-1 & $26.80 \pm 0.04$ & $20.99 \pm 0.13$ & $14.90 \pm 0.13$ & $13.46 \pm 0.26$ & $9.86 \pm 0.17$ & $6.59 \pm 0.18$ & $4.09 \pm 0.26$ & $3.30 \pm 0.19$ \\
Asia-I & $29.65 \pm 0.06$ & $24.28 \pm 0.22$ & $13.45 \pm 0.07$ & $11.86 \pm 0.40$ & $7.72 \pm 0.33$ & $3.66 \pm 0.13$ & $5.76 \pm 0.32$ & $3.61 \pm 0.12$ \\
\hline
\end{tabular}

Values are given as the mean \pm standard errors mean (SEM).

of $1.0 \mathrm{ml} \mathrm{min} \mathrm{m}^{-1}$. Standards of sugars were purchased from Sigma-Aldrich, St. Louis, MO, USA and used for quantification. Insect honeydew samples were weighed and dissolved in $1 \mathrm{ml}$ of $50 \%$ acetonitrile solution and filtered in $0.45 \mu \mathrm{m}$ syringe filter (Millipore, Billerica, MA, USA) and preserved in glass tubes at $-20^{\circ} \mathrm{C}$ for HPLC analysis. $10 \mu \mathrm{l}$ from the stored samples were injected in HPLC column.

\section{Identification of volatiles by Gas Chromatography- Mass Spectrometry analysis}

The honeydew volatiles were extracted of from insect using HPLC graded Hexane (Sigma-Aldrich ${ }^{\circledR}$ ) and analyzed on a gas chromatograph (HP6890; Agilent Technologies USA Ltd) directly linked to a HP5973 mass selective detector (Agilent Technologies) operated in electron impact mode (source temperature $230^{\circ} \mathrm{C}$; transfer line $250^{\circ} \mathrm{C}$ ). The HP-5 MS phenyl methyl siloxane non polar capillary column $(0.25 \mathrm{~mm} \times 30 \mathrm{~m}$ $\mathrm{x} 0.25 \mu$.) $\max 350^{\circ} \mathrm{C}$ (Agilent part No 190915 - 433) was used for the separation of fractions. The mobile phase was Helium 99.999\% purity (Praxair India Ltd) passed through the universal trap for removing the contaminants. The split inlet was used with split ratio of 50:1 and inlet temperature of $280^{\circ} \mathrm{C}$. The oven temperature program was set at $70^{\circ} \mathrm{C} \mathrm{min}{ }^{-2}$ with 2 minutes hold and a ramp of $10^{\circ} \mathrm{C}$ min $^{-1}$ till $260^{\circ} \mathrm{C}$ and held for 5 minutes with column flow of $1 \mathrm{ml} / \mathrm{min}$. The mass spectral detector was maintained at a temperature of $280^{\circ} \mathrm{C}$ with the interface temperature of $230^{\circ} \mathrm{C}$. The mass spectra created using the MS was compared with the Wiley mass spectral library (Wiley 2012 and NIST 2012 version).

\section{RESULTS AND DISCUSSION}

\section{HPLC analysis of sugars}

HPLC analysis of insect honeydew sugars and phloem sap showed variation in the quantity of sugars (Table 1 ). Carbohydrates in honeydew contained mainly reducing sugars such as glucose and fructose, non-reducing sugars (sucrose, trehalose and melezitose). Ribose, glucose, fructose, trehalose were significantly abundant in honeydew and phloem sap, compared to arabinose, melezitose and maltose (Figure 2). Ribose accounted for about $40 \%$ in plant sap and 27 and $30 \%$ in MEAM-I and Asia I genotype, respectively (Figure 3). Interestingly, insect sugars, trehalose and melezitose were recorded intrace amount in the phloem sap.

Major insect honeydew compounds are ribose, sucrose, glucose, fructose and trehalose. Honeydew acts as a kairomonal resource for insect parasitoids (Shimron et al., 1992; Romeis and Zebitz, 1997). The study 

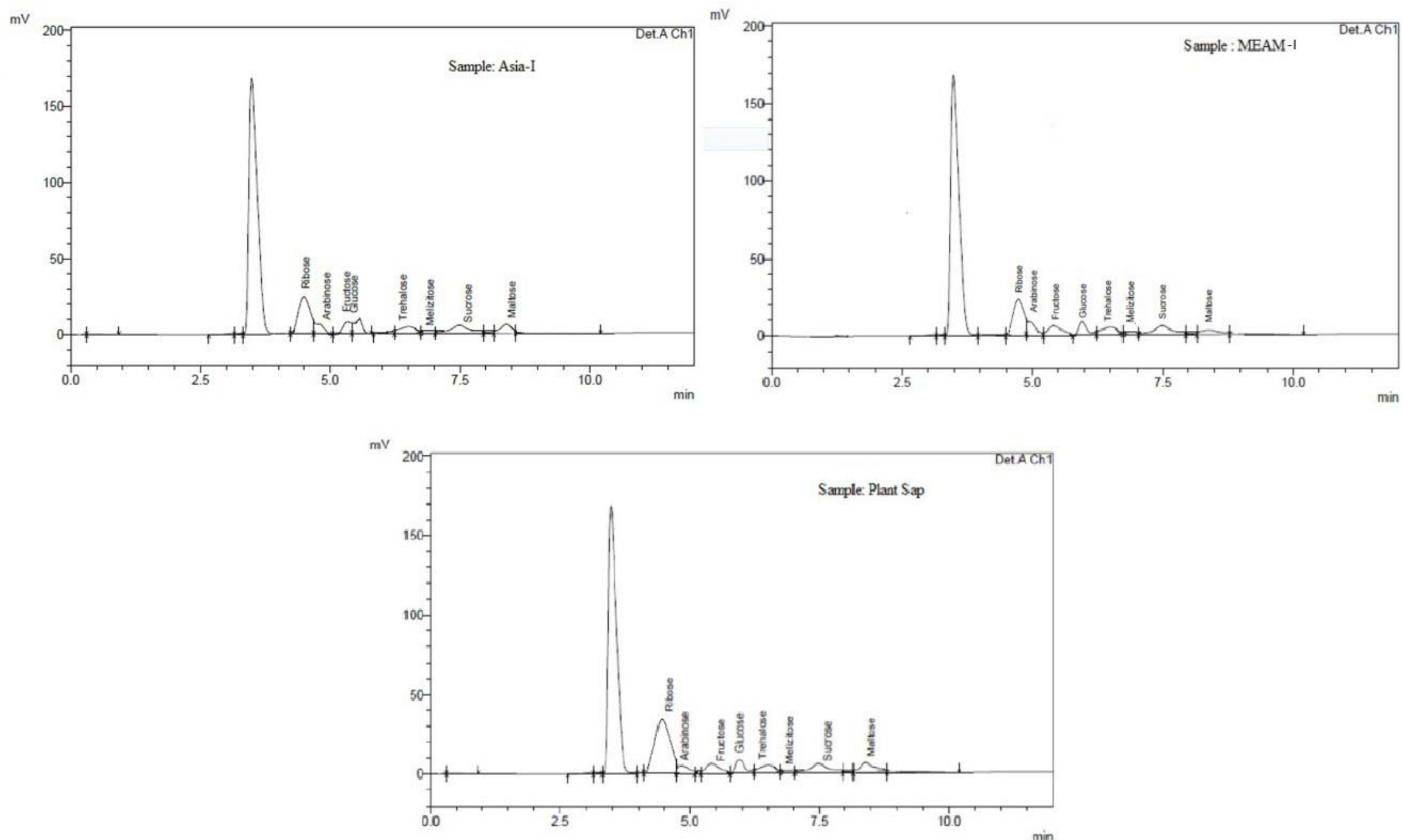

Figure 2. HPLC chromatography peaks from the honeydew samples collected from Plant sap (a), B. tabaci genetic group MEAM-I (b) and Asia-I (c) respectively.

conducted by Mandour et al. (2005) showed that parasitoid Encarsia bimaculata used honeydew as a contact kairomone to locate its host. When treated with glucose, fructose, trehalulose and trehalose E. bimaculata females aggregate in patches and their longevity is also increased. Trehalose was reported the highest response to parasitoids. The present results showed that honeydew composition vary in B. tabaci genetic groups and plant sap. Trehalose is known to be an insect blood sugar and also plays a vital role in microbial growth particularly endosymbionts and 


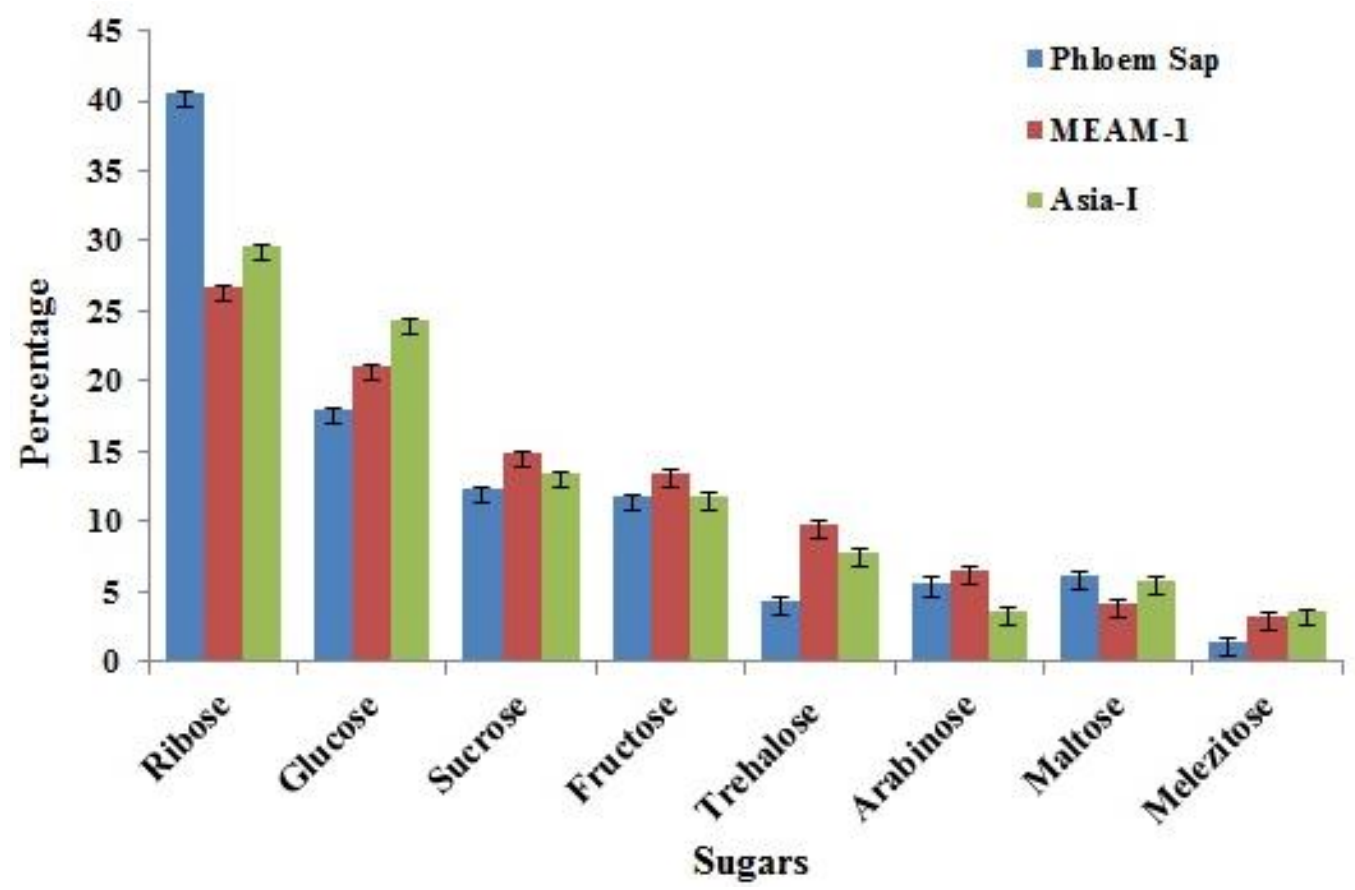

Figure 3. Graphical representation of percentage of sugars in honeydew of $B$. tabaci genetic groups MEAM-I, Asia-I and plant sap.

Table 2. Indicates volatiles percentage matching and abundance in Honeydew sample MEAM-I.

\begin{tabular}{|c|c|c|c|c|c|c|}
\hline PEAK NO & RT & MOL WT & COMPOUND & IONS & \%МATCH & ABUNDANCE \\
\hline 1 & 4.095 & 128.16 & $\mathrm{n}$-Nonane & $15,29,43,50,57,71,77,85,99,128$ & 95 & $8 \mathrm{~L}$ \\
\hline 2 & 4.5 & 142.14 & $\begin{array}{l}\text { 3-Cyclohexyl- } \\
\text { Propanol }\end{array}$ & $15,29,41,55,67,82,91,96,109,124$ & 64 & $7.2 \mathrm{~L}$ \\
\hline 3 & 6.24 & 142.17 & $\mathrm{n}$-Decane & $14,29,43,57,71,77,85,99,113,142$ & 95 & $13 \mathrm{~L}$ \\
\hline 4 & 7.98 & 156.19 & 2-Methyldecane & $14,29,43,57,71,85,99,112,140,156$ & 95 & $3 \mathrm{~L}$ \\
\hline 5 & 8.66 & 134.11 & $\begin{array}{l}\text { o- } \\
\text { Cymene } \$ \$ \text { Benzene }\end{array}$ & $15,27,39,51,58,65,77,91,93,103,119,134$ & 94 & $2 \mathrm{~L}$ \\
\hline 6 & 9.03 & 156.19 & $\mathrm{n}$-Undecane & $14,29,32,43,57,71,77,85,99,113,127,156$ & 95 & $9 \mathrm{~L}$ \\
\hline 7 & 9.312 & 150.05 & Propyl disulfide & $15,27,33,43,55,66,73,79,89,108,150$ & 85 & $5 \mathrm{~L}$ \\
\hline 8 & 12.19 & 170.20 & n-Dodecane & $15,29,43,57,71,85,91,98,112,127,140,170$ & 96 & $5 \mathrm{~L}$ \\
\hline 9 & 12.64 & 178.09 & $\begin{array}{l}\text { Disulfide, bis(1- } \\
\text { methylpropyl) }\end{array}$ & $\begin{array}{l}15,29,41,45,57,68,75,85,93,107,122,149 \\
178\end{array}$ & 97 & $30 \mathrm{~L}$ \\
\hline
\end{tabular}

also essential for insect metabolic activities (Wackers et al., 2008). Trace amount of trehalose was detected in plant sap, which plays an important role in mediating ant homopteran mutualisms and also tritropic interaction.

\section{GC-MS analysis of volatiles in Honeydew Samples}

GC-MS analyses identified volatiles components from both the sample of $B$. tabaci genotypes, specifically collected from crude honeydew in HPLC graded Hexane (Sigma-Aldrich ${ }^{\circledR}$ ). The analysis revealed the following viz n-nonane, n-decane, 2-methyldecane, o-cymene benzene, n-undecane, propyl disulfide, n-dodecane, disulfide, bis (1-methylpropyl) are common in both honeydew of $B$. tabaci genetic groups. Interestingly, 3cyclohexyl-propanol is absent in Asia-I and n-propyl secbutyl disulfide is not detected in MEAM-I group (Figure 4a and $b$ ). The percentage matching and abundance of volatiles compounds are given in Table 2 and 3 . Honeydew excreted by hemipteran serves as food source for predators like lace wings. None of the above mentioned volatiles reported in honeydew of whitefly, $B$. tabaci. Only undacane was detected on tea aphid body surface with $n$-hexane rinse attracted natural enemies (Han, 2001). Volatiles are reported to be involved in 

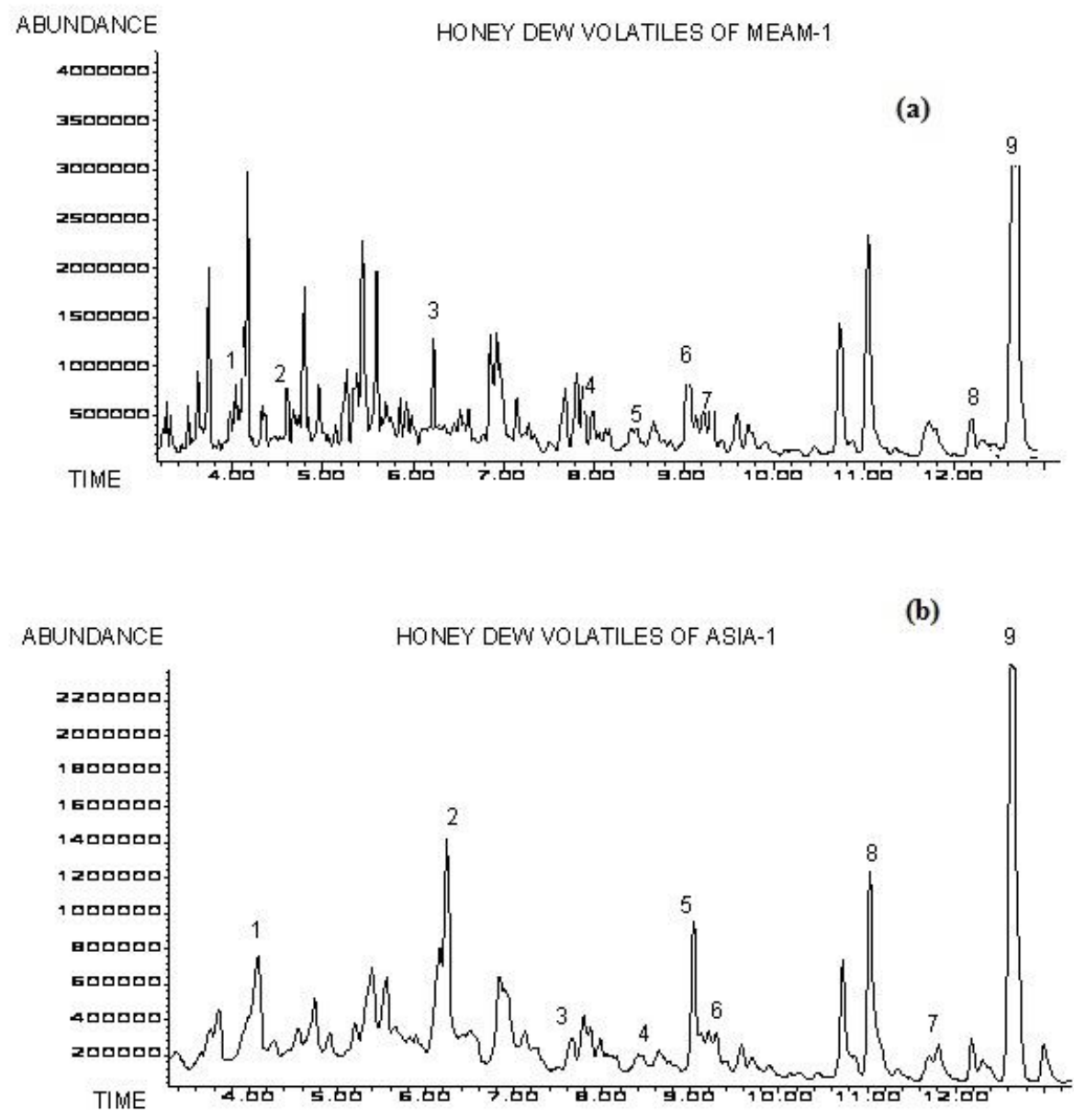

Figure $4 a$ and b. GC-MS volatile peaks from Honeydew samples of $B$. tabaci genotypes Asia-I and MEAM-I.

Table 3. Indicates volatiles percentage matching and abundance in Honeydew sample Asia-I.

\begin{tabular}{cccllccc}
\hline PEAK NO & RT & MOL WT & COMPOUND & IONS & \%MATCH & ABUNDANCE \\
\hline 1 & 4.095 & 128.16 & n-Nonane & $15,29,43,50,57,71,77,85,99,128$ & 96 & $7 \mathrm{~L}$ \\
2 & 6.24 & 142.17 & n-Decane & $14,29,43,57,71,77,85,99,113,142$ & 95 & $13 \mathrm{~L}$ \\
3 & 7.98 & 156.19 & 2-Methyldecane & $14,29,43,57,71,85,99,112,140,156$ & 95 & $3 \mathrm{~L}$ \\
4 & 8.66 & 134.11 & -- & Cymene\$\$ Benzene & $15,27,39,51,58,65,77,91,93,103,119,134$ & 94 & $2 \mathrm{~L}$ \\
5 & 9.1 & 156.19 & n-Undecane & $14,29,32,43,57,71,77,85,99,113,127,156$ & 90 & $10 \mathrm{~L}$ \\
6 & 9.312 & 150.05 & Propyl disulfide & $15,27,33,43,55,66,73,79,89,108,150$ & 89 & $4 \mathrm{~L}$ \\
7 & 12.19 & 170.20 & n-Dodecane & $15,29,43,57,71,85,91,98,112,127,140,170$ & 96 & $3 \mathrm{~L}$ \\
8 & 11.02 & 164.07 & $\begin{array}{l}\text { n--Propyl sec-butyl } \\
\text { disulfide } 15,29,43,57,66,73,87,108,122,164\end{array}$ & 93 & $12.5 \mathrm{~L}$ \\
& & & Disulfide, bis $(1-$ & $15,29,41,45,57,68,75,85,93,107,122,149$, & 97 & $24 \mathrm{~L}$ \\
\hline
\end{tabular}

natural enemy calling and found to be useful in biological control. This is the first report of these honeydew volatiles collected from $B$. tabaci genetic groups MEAM-I and Asia-I fed on cotton. Tritrophic interactions involving whitefly-species of ants and parasitoid/predators determine the population dynamics of whitefly infestation in the field. The composition of the excreted has a direct bearing on the species of ants attracted and this impacts 
parasitism or predations.

Whiteflies attack recently reported from Punjab agricultural university July 2016 which caused havoc on cotton, especially Bt cotton in Punjab province of India and Pakisthan. Indiscriminate application of pesticides without understanding the physiology of the insect honeydew excretion and its ecological impact only confounds the problem. The information is all the more important considering the pest is one of the most important vectors, polyphagous and can quickly develop resistance to insecticides. Furthermore, classification of $B$. tabaci into subgroups indicates genetic/physiological variations. Thus, understanding of the composition of honeydew is important. In the present study, volatiles common in honeydew samples of both genetic groups may be used as effective semiochemicals in enhancing natural enemies. Further studies on the role of honeydew in attracting natural enemies would facilitate devising an ecologically sound management of $B$. tabaci genetic groups.

\section{CONCLUSION}

Honeydew composition is an important factor in mediating ant-homopteran mutualisms and also tritropic interaction involving natural enemies. Present study show that honeydew composition differs quantitatively within genetic groups of $B$. tabaci. The known differences in ant preference for different species as studied in the case of aphids, is supported by the results of this study. This in turn shows that ant tending may itself influence honeydew composition and may incur metabolic costs on aphids and whiteflies. Volatiles emitted by the honeydews also aid in attracting natural enemies. The commonly observed volatiles in both genetic groups of $B$. tabaci can be used in an effective eco-friendly management programme of these insect pests. Further studies on sugar composition in relation to species of ants attracted and its impact on predation/parasitism is needed.

\section{CONFLICT OF INTEREST}

The authors declare that they have no conflict of interest.

\section{ACKNOWLEDGMENTS}

This paper is part of the doctoral degree work of the senior author. Financial support received for the "Outreach Programme on Management of Sucking Pests in Horticultural Crops" from the Indian Council for Agricultural Research (ICAR), New Delhi, India, is gratefully acknowledged. We are thankful to the director at the Indian Institute of Horticultural Research (IIHR) for the support and facilities.

\section{REFERENCES}

Bates, R. B., Byrne, D. N., Kane, V. V, Miller, W. B., \& Taylor, S. R. (1990). N. M. R characterization of trehalose from the excrement of the sweet potato whitefly, Bemisia tabaci. Carbohydrate Research, 201, 342-345.

Brown, P. A. (1997). A review of techniques used in the preparation, curation and conservation of microscope slides at The Natural History Museum, London. The Biology Curator, Issue 10, Special Supplement, 1-34.

Burger, J. M. S., Gort, G., Lenteren, V. J. C., \& Vet, L. E.M. (2004). Natural history of whitefly in Costa Rica: an evolutionary starting point. Ecological Entomology, 29, 150163.

Byrne, D. N., \& Miller, W. B. (1990). Carbohydrates and amino acid composition of phloem sap and honeydew produced by Bemisia tabaci. Journal of Insect Physiology. 36, 433- 439.

Davidson, E. W. Rosell, R. C., \& Hendrix, D. L. (1994). Microorganisms Influence the composition of honeydew produced by the silverleaf whitefly, Bemisia argentifolii. Journal of Insect Physiology, 40,1069-1079.

De Barro, P. J., Liu, S. S., Boykin, L. M., \& Dinsdale, A. (2011). Bemisia tabaci: a statement of species status. Annual Review of Entomology, 56, 1-19.

Dinsdale, A., Cook, L., Riginos, C., Buckley, Y. M., \& De Barro, P. J. (2010). Refined global analysis of Bemisia tabaci (Hemiptera: Sternorrhyncha: Aleyrodoidea: Aleyrodidae) mitochondrial cytochromeoxidase I to identify species level genetic boundaries. Annual Review of Entomological Society America, 103,196-208.

Fischer, M. K., \& Shingleton, A. R. (2001). Host plant and ants influence the honeydew sugar composition of aphids. Functional Ecology, 15, 544-550.

Fischer, M.K., Völkl, W., \& Hoffmann, K. H. (2005). Honeydew production and honeydew sugar composition of polyphagous black bean aphid, Aphis fabae (Hemiptera: Aphididae) on various host plants and implications for ant-attendance. European Journal of Entomology, 102, 155-160

Fisher, D. B., Wright, J. P., \& Miller, T. E. (1984). Osmoregulation by the aphid Myzus persicae: A physiological role for honeydew oligosaccharides. Journal of Insect Physiology, 30, 387-393.

Golan, K., \& Najda, A. (2011). Differences in the sugar composition of the honeydew of polyphagous brown soft scale Coccushesperidum (Hemiptera: Sternorrhyncha: Coccoidea) feeding on various host plants. European Journal of Entomology, 108 (4), 705-709.

Han, B. Y. (2001). Attractive activity to natural enemies and component analysis of the rinses from tea aphid body surface. Acta Entomologica Sinica, 44(4), 541-547

Hendrix, D. L., \& Wei, Y. (1994). Bemisiose: an unusual trisaccharide in Bemisia honeydew. Carbohydrate Research, 253, 329-334.

Hendrix, D. L., Wei, Y., \& Leggett, J. E. (1992). Homopteran honeydew sugar composition is determined by both the insect and plant species. Comparitive Biochemical and Physiology, 101, 23-27

Hu, J., De Barro, P. J., Zhao, H., Wang, J., Nardi, F., \& Liu, S. S. (2011). An extensive field survey combined with a phylogenetic analysis reveals rapid and widespread invasion of two alien whiteflies in China. PLosOne, 6, e16061.

Isaacs, R., Byrne, D. N., \& Hendrix, D. L. (1998). Feeding rates and carbohydrate metabolism by Bemisia tabaci (Homoptera: Aleyrodidae) on different quality phloem saps. Physiological 
Entomology, 23, 241-248.

Johnson, M. W., Caprio, L. C., Lynch, J. A. , Tabashnik, B. E., Welter, S. C., \& Rosenheim, J. A. (1991). Yield response of fresh market tomatoes to greenhouse whitefly infestations in Hawaii. Pro. Agricultural Development in the American Pacific Crop Protection Conference, pp, 101-103.

Liu, S. S, De Barro, P. J., Xu, J., Luan, J. B., Zang, L. S., Ruan, Y. M., \& Wan, F. H. (2007). Asymmetric mating interactions drive widespread invasion and displacement in a whitefly. Science, 318, $1769-1772$

Liu, S. S., Colvin, J., De Barro, P. J. (2012). Species concepts as applied to the whitefly Bemisia tabaci systematics: how many species are there? Journal of Integrated Agriculture, 11, 176-186.

Mandour, N. S., Shunxiang, R., Baoli, Q., \& Wackers, F. (2005). Arrestment response of Eretmocerus species (Hymenoptera: Aphelinidae) near Furuhashii to Honeydew of Bemisia tabaci (Homoptera: Aleyrodidae) and its component carbohydrates. In: Proceedings of the Sixth Arabian Conference for Horticulture, 6, 311-319.

Martin, J. H. (1987). An identification guide to common whitefly pest species of the world (Homoptera, Aleyrodidae). Tropical Pest Management, 33, 298-322.

Romeis, J., \& Zebitz, C. P. W. (1997). Searching behaviour of Encarsiaformosa as mediated by colour and honeydew. Entomologia Experimentalis Applicata, 82, 299-309.

Sanchez-Mata, M. C., Camara-Hurtado, M., \& Diez-Marques, C. (2002). Identification and quantification of soluble sugars in green beans by HPLC. European Food Reserach Technology, 214(3), 254-258.

Shimron, O., Hefetz, A., Gerling, D. (1992). Arrestment responses of Eretmocerus species and Encarsiadeserti (Hymenoptera: Aphelinidae) to Bemisia tabaci honeydew. Journal of Insect Behavior, 5, 517-52

Simon, C., Frati, F., Beckenbach, A., Crespi, B., Liu, H., \& Flook, P. (1994). Evolution, weighting, and phylogenetic utility of mitochondrial gene sequences and a compilation of conserved polymerase chain reaction primers. Annual review of Entomological Society America, 87, 651-701.
Tarczynski, M. C., Byrne, D. N., \& Miller, W. B. (1992). High performance liquid chromatography analysis of carbohydrates of cotton-phloem sap and of honeydew produced by Bemisia tabaci feeding on cotton. Plant Physiology, 98, 753-756.

Tetyuk, O., Benning, U. F., \& Hoffmann-Benning, S. (2013). Collection and analysis of Arabidopsis phloem exudates using the EDTA-facilitated Method. Journal of Visualized Experiments, 80, e51111, doi:10.3791/51111

Volkl, W., Woodring, J., Fischer, M., Lorenz, M. W., \& Hoffmann, K. H. (1999). Ant-aphid mutualism: The impact of honeydew production and honeydew sugar composition on ant preferences. Oecologia, 118, 483-491

Wackers, F. L., Van Rijn Paul, C. J., \& Heimpel, G. E. (2008). Honeydew as a food source for natural enemies: making the best of a bad meal? Biological Control, 45,176-184.

Wilkinson, T. L., Ashford, D. A., Pritchard, J., \& Douglas, A. E. (1997). Honeydew sugars and osmoregulation in the pea aphid Acyrthosiphonpisum. Journal of Experimental Biology, 200, 2137-2143

Wool, D., Hendrix, D. L., \& Shukry, O. (2006). Seasonal variation in honeydew sugar content of galling aphids (Aphidoidea: Pemphigidae: Fordinae) feeding on Pistacia: host ecology and aphid physiology. Basic Applied Ecology, 7,141-151.

Zasada, I. A, Peetz, A., Howe, D. K., Wilhelm, L. J., Cheam, D. et al. (2014). Using Mitogenomic and Nuclear Ribosomal Sequence Data to Investigate the Phylogeny of the Xiphinemaamericanum Species Complex. PLoS ONE 9(2). 